\title{
Construção identitária das mulheres no campo da computação. Imagens reforçadas, distâncias ampliadas
}

\author{
Pricila Castelini', Marília Abrahão Amaral $^{12}$ \\ ${ }^{1}$ Programa de Pós-Graduação em Tecnologia e Sociedade - Universidade Tecnológica Federal do Paraná
} (UTFPR) Av. Sete de Setembro, 3165 - CEP 80230-901 - Curitiba - PR

${ }^{2}$ Departamento Acadêmico de Informática - Universidade Tecnológica Federal do Paraná (UTFPR).

pricilacas@hotmail.com,marilia.utfpregmail.com

\begin{abstract}
This paper analyzes identities of women build upon Programaê's images based on Discourse Analysis. These images sustain discursively representations of styles and identities formed socially, culturally, and historically that reinforces man/women, male/female binarism. In this theoretical perspective, we present 3 images of our corpus $(N=50)$ in order to highlight the reproduction of binarism in computation.

Resumo. Este artigo analisa, com base em Análise de Discurso, as identidades construídas das mulheres na divulgação do Programaê. $O$ Programaê divulga imagens que constroem discursivamente representações de estilos e identidades formadas socialmente, culturalmente e historicamente que reforçam os binarismos homem/mulher, masculino/feminino. Nessa perspectiva teórica, são apresentadas três imagens do corpus $(N=50)$ para destacar a reprodução e reforço dos binarismos da computação.
\end{abstract}

\section{Contexto inicial}


proposta do programa é aproximar a programação ao cotidiano de jovens, mas apesar de a proposta ser a todos, exclui aquelas pessoas que não se identificam com a representação dos personagens que o programa propõe. Turkle \& Papert (1990) indicam que a computação tem um histórico de preconceito e discriminação contra mulheres .

O Programaê utiliza-se de redes sociais a fim de atingir o público-alvo do programa. Até a análise deste artigo, foram disponibilizadas 850 imagens, em grande parte criação própria, bem como vídeos com pessoas contratadas com objetivo de popularizar suas ações. O corpus deste artigo é composto de 50 imagens e oito vídeos.

A análise das imagens e vídeos são à luz das lentes epistemológicas da análise de discurso (AD) proposta por Michel Pêcheux. Para as análises, utiliza-se a noção de memória e discurso. Memória é o já dito no discurso; e discurso são os efeitos de sentido entre interlocutores tendo em vista que as relações de sentido no discurso e na semântica possuem uma formalização dialogável [PÊCHEUX, 1982].

1 Trata-se de um espaço para mostrar ao mundo que a programação é para todos, mobilizando cada vez mais pessoas em torno dessa causa. Para isso, ele reúne as melhores e mais simples ferramentas para aprender e ensinar a programar. Todas elas são gratuitas, em português e não exigem nenhum conhecimento prévio em programação. O propósito é "agregar ideais, soluções e dicas de gente experiente e inspiradora" (PROGRAMAÊ, 2017). Disponível em: http://programae.org.br/\#saibamais Acesso em: 02 de abril de 2017. 
Já que os discursos permeiam a vida das pessoas e influenciam no modo de agir e pensar e são, em geral, perpetuados nos espaços de convivência (escola, igreja, família, mídia, ciberespaço, web), analisa-se de que forma esses espaços podem reforçar questões relacionadas aos binarismos homem/mulher. A seção 2 traça um olhar sobre os percursos da construção identitária das mulheres na história; e seção 3 analisa três imagens disponibilizadas via web.

\section{Percursos das mulheres na história}

As manifestações contra preconceito e discriminação das mulheres começaram a adquirir visibilidade com o "sufragismo", um movimento para estender o direito ao voto para as mulheres. Esse movimento ganhou amplitude no Ocidente e foi reconhecido como a "primeira onda do feminismo" [LOURO, 1998, p. 15]. No final da década de 1960, o feminismo se preocupava com questões políticas, sociais, legais, criticando a noção de mulher como ser universal. Foi um momento de estudos e lutas do movimento feminista, exigindo o reconhecimento das diferenças e denominado como a "segunda onda do feminismo" [LOURO, 1998, p. 15].

Com esses debates envolvendo estudiosas, militantes, críticos e críticas, e considerando a importância de expandir o feminismo para um grupo diversificado de pessoas com um conjunto de identidades variadas, é problematizado o conceito de gênero que faz parte da chamada "terceira onda" [LOURO, 1998, p. 15]. Embora considere de real importância o posicionamento de "terceira onda", este trabalho tem como recorte a imagem das mulheres em espaços da área de computação.

Na área da computação, há evidências de que as mulheres são excluídas, e suas contribuições são invisibilizadas. Em uma discussão sobre pluralismo epistemológico Turkle \& Papert (1990) dizem que a computação canônica, através do ensino, exclui pensamentos diferentes. Este artigo defende que a computação deve buscar novas epistemologias; para esse fim, contribui com Análise de Discurso sobre os papéis estereotipados no Programaê.

No livro Unlocking the Clubhouse: Women in computing, Margolis \& Fisher (2002) escrevem sobre a "quase" ausência de vozes femininas em locais de trabalho, na ciência, tecnologia, e na sociedade, e em outros espaços são construídos em torno de modelos culturais predominantemente masculinos [MARGOLIS; FISHER, 2002, p. 2]. Janete Abbate (2012) evidencia a predominância de homens nos cursos da área computação e relata que a participação das mulheres envolve suposições generalizadas sobre habilidades técnicas que afetaram tanto a inclinação das mulheres para escolher a computação e suas mudanças de contratos imperativos culturais que são diferentes para homens e mulheres, no mercado de trabalho, por exemplo, pois há estereótipos populares sobre o que é a computação e para quem é melhor.

\section{AD das imagens de divulgação do Programaê}

Os discursos se relacionam pelo processo definido como relação de sentidos, em que um discurso se sustenta em outro discurso, que circulou antes em outro lugar e retorna como memória [Pêcheux, 1982].

As percepções das imagens nos meios de comunicação são condicionadas politicamente, socialmente e culturalmente. Magalhães (2005) enfatiza que "os 
produtores dos textos publicitários moldam as identidades dos leitores mediante as percepções da realidade que são comuns entre ambos; apenas o que valoriza a autoidentidade do leitor e da leitora é considerado” [MAGALHÃES, 2005, p. 241].

As imagens ${ }^{2}$ analisadas produzem e instituem informações que "não apenas educam homens e mulheres, meninos e meninas, mas atuam na construção de suas identidades culturais”[FURLANI, 2009, p. 132-133]. Os diversos conteúdos atuam também na construção identitária dos indivíduos.



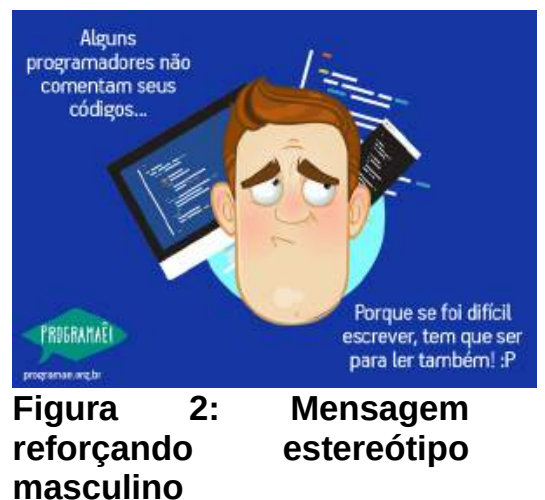

masculino

A personagem mulher na Figura 1 é loira, branca, com estereótipo de feminilidades que exclui mulheres e meninas que não se identificam com tal estereótipo. O personagem homem é branco, guerreiro, como todos os personagens homens que é disponibilizado nas comunicações do Programaê, como exemplo a Figura 2.

“Alguns programadores não comentam seus códigos...” Além da representação do "eu” ser de um homem branco, a mensagem verbal não incluí mulheres, ou neste caso - programadoras? Ao singularizar sexo e gênero, as figuras esconde e omite diversas maneiras de feminilidades e masculinidades na sociedade. Além de demonstrar papéis que são esperados que as pessoas assumam na sociedade, de certo modo ocultando a cultura, a política, a ideologia.

O personagem homem, branco da Figura 2 é representado em 15 das imagens analisadas via web pelo Programaê. A figura de um homem e o texto verbal remetem-se a imagem de nerd. As características das pessoas nerd está marcada no imaginário da computação e no imaginário popular atrelado à figura masculina.

Entre repetições e apagamentos, o termo nerd associado à imagem da pessoa programadora existe porque há uma relação entre enunciado e sujeito constituída pelo histórico, e, deste modo, pela memória. A memória é para Pêcheux (1998) crucial para compreender a relação com o discurso, pois no processo de repetição a imagem é formada e instaurada no imaginário social, e quando apagada, ou seja, quando não é enunciada pelos sujeitos no ato de fala é esquecida. Tal esquecimento é temporário, toda vez que o termo aparece retorna como memória as construções sociais, culturais e

2 Fonte: Website: http://programae.org.br/ ; Facebook: https://www.facebook.com/programaebrasil/ ; Instagram: https://www.instagram.com/programaebrasil/ 
ideológicas associado à imagem construída, neste caso, a relação entre o nerd e a computação.

A Figura 3 apresenta uma das personagens que circula nas ferramentas de comunicação do Programaê. Entre as poucas mulheres que são representadas nas imagens, está uma princesa.



Figura 3: Princesa programadora

Uma personagem princesa acompanhada de um texto verbal: "Aquele momento em que você descobre que a princesa é de exatas” retorna o imaginário de que as mulheres que se veem princesas também podem ser da área. Porém, ao utilizar uma personagem princesa como representação, afasta as mulheres que não se identificam com tal construção do "eu” e reforça estereótipos de beleza e submissão.

Seria a linguagem então um meio para legitimar (ou não) a construção histórica de uma sociedade sexista, misógina, machista? Furlani (2009) relata que a linguagem é aspecto central da problematização sobre assuntos sociais e culturais. Neste contexto, as imagens possuem sentidos, os textos das propagandas e outras mídias ensinam como as pessoas devem relacionar-se com o mundo, e quais valores devem ser aceitos socialmente para cada pessoa. E desse modo, sugerem certos modelos, comportamentos que excluem, que contribuem, reforçam, mantêm e regulam regras sociais.

No caso das 50 imagens analisadas, apesar de a proposta do Programaê ser de inclusão de todos e todas na área de computação, ela ainda é contraditória, pois demonstra estereótipos de mulheres como princesas e reforça o conceito de que pessoas que atuam na computação são majoritariamente homens brancos heterossexuais, já que descartam outros personagens, como por exemplos, mulheres que não se identificam com a personagem princesa, negros e negras, pessoas com deficiência.

À medida que as lutas do feminismo tentam liberar as mulheres da imagem associada à beleza, fragilidade, estereótipos, o Programaê acredita aproximar meninas/mulheres da computação por meio de uma representação que reforça identidades hegemônicas, que exclui outras e podem contribuir, manter, regular e subverter regras e modelos. Além de explicitar as identidades e fixar, posicionam os indivíduos em um modelo de patriarcado universal.

\section{Considerações finais}

Os discursos, as imagens, vídeos sobre beleza e representação de personagens de princesas podem construir identidades, construções imaginárias e discursivas que excluem pessoas, ou seja, criam modelos estereotipados no imaginário social. A AD, nesta perspectiva é um caminho para o estudo do discurso em conteúdos digitais / na 
web, tendo em vista que as relações estabelecidas nestes espaços e fora deles, com os sujeitos envolvidos são construídas historicamente.

O Programaê, em sua proposta, aponta para que os e as participantes venham a conhecer e desenvolver a computação, mas de certa forma excluem sujeitos que não se identificam com os estereótipos formados nos personagens. Os desdobramentos dessas representações nas imagens do Programaê constroem e reforçam que a computação ainda é um espaço de predominância da figura masculina, e para as mulheres se aproximarem da área são estereotipadas com papéis de princesas e vídeos que as associam à beleza. As representações das imagens do Programaê produzem maneiras de ser, agir e pensar ao demonstrar homens e mulheres e quais os valores que são aceitos socialmente para cada um e uma.

\section{Referências}

Abbate, J. "Recoding gender: women'a changing participation in computing”. [S.l.]: MIT Press, 2012.

Furlani, J. "Representações da mulher e do feminismo na mídia impressa brasileira desconstruindo significados na Educação Sexual”. Sexualidade / Secretaria de Estado da Educação. Superintendência de Educação. Departamento de Diversidades. Núcleo de Gênero e Diversidade Sexual. - Curitiba : SEED - Pr. Curitiba: [s.n.], 2009. p. 216.

Louro, G. L. "Gênero, sexualidade e educação: uma perspectiva pós-estruturalista”. Petrópolis: Editora Vozes: CNTE, Confederação Nacional dos Trabalhadores em Educação, 1998.

Magalhães, I. Análise do discurso publicitário. v. 4, n. 1 e 2, p. 231-260, 2005.

Margolis, J; Fisher, A. “Unlocking the clubhouse: Women in computing”. 2002. ed. [S.I: s.n.], 2002.

Pêcheux, M. "Ler o arquivo hoje”. Gestos de leitura: da história no discurso. 1994. ed. São Paulo, SP: Editora da Unicamp, 1982. p. 55-66.

Programaê. “Website da empresa de programação para jovens do Brasil”. 2017. Disponível em: http://programae.org.br/. Acesso em: 02 de abril de 2017.

Turkle, S; Papert, S. "Epistemological Pluralism and the Revaluation of the Concrete". Journal of Mathematical Behavior. v. 11, n. 1, 1991, 1990 1990. Disponível em: <http://www.papert.org/articles/EpistemologicalPluralism.html>. Acesso em: 11 abr. 2016. 